Thorax, 1980, 35, 375-378

\title{
Partial effective times of the forced expiratory spirogram in health and mild airways obstruction
}

\author{
J JORDANOGLOU, G TATSIS, M VESLEMES, S CHARALAMPAKIS, AND \\ C HADJISTAVROU
}

From the Respiratory Unit, "Evangelismos" Hospital, Athens, Greece

ABSTRACT The partial effective times of the expiratory spirogram were calculated in 80 normal nonsmoking subjects aged from 20 to 69 years and in 30 patients aged from 30 to 58 years with chronic bronchitis. Of these patients, 28 had a normal $\mathrm{FEV}_{1} / \mathrm{FVC}$ ratio, while the other two had a low ratio. Partial effective times were calculated for $10 \%$ segments of the expired FVC from total lung capacity $(0 \% \mathrm{FVC})$ to residual volume (100\% FVC) and became progressively longer after $50 \%$ of the FVC had been expired in normal subjects. The elongation of the partial effective times was more pronounced with age. In the patients with simple chronic bronchitis (normal $\mathrm{FEV}_{1} / \mathrm{FVC}$ ratio) the partial effective times were longer than normal after $50 \%$ of the FVC had been expired and after $10 \%$ of the FVC had been expired in the two patients with chronic bronchitis and low $\mathrm{FEV}_{\mathbf{1}} / \mathrm{FVC}^{\mathrm{F}}$ ratio. The partial effective times of the forced expiratory spirogram, especially that at the $80-90 \%$ part of the FVC, seem to be very sensitive indices for the early detection of mild airways obstruction.

The effective time (or the equivalent mean transit time) of the maximal expiratory spirogram has been considered as a sensitive test parameter for the detection of airways obstruction. ${ }^{1-6}$ However, in patients suffering from simple chron:c bronchitis and in a few bronchitics with low $\mathrm{FEV}_{1} / \mathrm{FVC}$ ratios the effective time is very close to the upper normal limit. Furthermore, we have noticed that in several patients with chronic nonspecific lung disease and different $\mathrm{FEV}_{1} / \mathrm{FVC}$ ratios the effective time of the spirogram is nearly the same. In this paper, we present the results of a study, the purpose of which was to increase the ability for discrimination between normal subjects and patients suffering from mild airways obstruction by means of the partial effective times of the forced expiratory spirogram.

\section{Methods}

Eighty normal non-smoking subjects ( 45 men and 35 women) aged from 20 to 69 years were studied. In these subjects there was no history of lung, heart, or thoracic wall disease. Physical examination and the chest radiograph revealed no abnormality and the forced vital capacity

Address for reprint requests: Professor J Jordanoglou, Sotiria Hospital, 152 Mesogion Avenue, Athens, Greece.
(FVC), forced expiratory volume in one second $\left(\mathrm{FEV}_{1}\right)$, and the $\mathrm{FEV}_{1} / \mathrm{FVC}$ rat'o were within one standard deviation of the predicted normal values. $^{7}$ We also studied 28 patients ( 15 men and 13 women), aged from 30 to 58 years, suffering from simple chronic bronchitis-that is, from chronic cough and mucoid expectoration (less

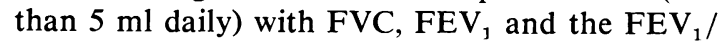
FVC ratio within normal limits ( $\leqslant 1$ SD). Furthermore, we studied two women aged 38 and 52 years suffering from chronic bronchitis with $\mathrm{FEV}_{1} / \mathrm{FVC}$ ratios lower than the predicted normal values by $13 \%$ and $15 \%$ (that is, by about 2 SD). The normal values for the effective time of the forced expiratory spirogram, which we shall call total effective time $\left(\right.$ teff $\left._{\mathrm{T}}\right)$ as well as for the partial effective times (teff ${ }_{p}$ ) were obtained from the 80 normal non-smoking subjects (table). The subjects, seated and with the nose clipped, expired forcibly and as long as they could through a mouthpiece (id $=2.55 \mathrm{~cm}$ ) into a waterfilled spirometer. Three maximal expiratory efforts from total lung capacity (TLC, $0 \%$ FVC) to residual volume (RV, $100 \%$ FVC) were performed. The expirograms ( $F V C-t$ curves) were recorded on a paper on which 1 litre (ATPS) = $33.2 \mathrm{~mm}$. The speed of the paper was exactly 20 $\mathrm{mm} / \mathrm{s}$. The curve with the maximum FVC was chosen for analysis. In this FVC-t curve the 
Table Partial effective times at each $10 \%$ of $F V C$ and total effective time in normal subjects

\begin{tabular}{|c|c|c|c|c|c|}
\hline \multirow{2}{*}{$\begin{array}{l}\text { FVC } \\
\text { percentage } \\
\text { sub- } \\
\text { divisions }\end{array}$} & \multicolumn{5}{|c|}{ Age groups (yr) } \\
\hline & $\begin{array}{l}20-29 \\
(n=29)\end{array}$ & $\begin{array}{l}30-39 \\
(\mathrm{n}=13) \\
\text { Mean va }\end{array}$ & $\begin{array}{c}40-49 \\
(n=16) \\
e s(S D) o\end{array}$ & $\begin{array}{l}50-59 \\
(\mathrm{n}=11) \\
\text { eff }(s)\end{array}$ & $\begin{array}{l}60-69 \\
(n=11)\end{array}$ \\
\hline $0-10$ & $\begin{array}{c}0.0305 \\
(0.0085)\end{array}$ & $\begin{array}{c}0.0308 \\
(0.0093)\end{array}$ & $\begin{array}{c}0.0325 \\
(0.0084)\end{array}$ & $\begin{array}{c}0.0304 \\
(0.0062)\end{array}$ & $\begin{array}{c}0.0326 \\
(0.0080)\end{array}$ \\
\hline $10-20$ & $\begin{array}{c}0.0276 \\
(0.0098)\end{array}$ & $\begin{array}{c}0.0292 \\
(0.0064)\end{array}$ & $\begin{array}{c}0.0266 \\
(0.0057)\end{array}$ & $\begin{array}{c}0.0261 \\
(0.0076)\end{array}$ & $\begin{array}{c}0.0251 \\
(0.0084)\end{array}$ \\
\hline $20-30$ & $\begin{array}{c}0.0291 \\
(0.0077)\end{array}$ & $\begin{array}{c}0.0338 \\
(0.0071)\end{array}$ & $\begin{array}{c}0.0322 \\
(0.0080)\end{array}$ & $\begin{array}{c}0.0289 \\
(0.0081)\end{array}$ & $\begin{array}{r}0.0286 \\
(0.0063)\end{array}$ \\
\hline $30-40$ & $\begin{array}{r}0.0345 \\
(0.0069\end{array}$ & $\begin{array}{c}0.0365 \\
(0.0114)\end{array}$ & $\begin{array}{c}0.0347 \\
(0.0081)\end{array}$ & $\begin{array}{c}0.0302 \\
(0.0058)\end{array}$ & $\begin{array}{c}0.0364 \\
(0.0090)\end{array}$ \\
\hline $40-50$ & $\begin{array}{c}0.0390 \\
(0.0091)\end{array}$ & $\begin{array}{c}0.0454 \\
(0.0149)\end{array}$ & $\begin{array}{c}0.0403 \\
(0.0097)\end{array}$ & $\begin{array}{c}0.0387 \\
(0.0102)\end{array}$ & $\begin{array}{c}0.0452 \\
(0.0117)\end{array}$ \\
\hline $50-60$ & $\begin{array}{c}0.0488 \\
(0.0106)\end{array}$ & $\begin{array}{c}0.0554 \\
(0.0146)\end{array}$ & $\begin{array}{c}0.0569 \\
(0.0167)\end{array}$ & $\begin{array}{c}0.0551 \\
(0.0111)\end{array}$ & $\begin{array}{c}0.0807 \\
(0.0278)\end{array}$ \\
\hline $60-70$ & $\begin{array}{c}0.0662 \\
(0.0119)\end{array}$ & $\begin{array}{c}0.0827 \\
(0.0249)\end{array}$ & $\begin{array}{c}0.0803 \\
(0.0219)\end{array}$ & $\begin{array}{c}0.0926 \\
(0.0170)\end{array}$ & $\begin{array}{c}0.1282 \\
(0.0352)\end{array}$ \\
\hline $70-80$ & $\begin{array}{c}0.0930 \\
(0.0242)\end{array}$ & $\begin{array}{c}0.1523 \\
(0.0785)\end{array}$ & $\begin{array}{c}0.1491 \\
(0.0408)\end{array}$ & $\begin{array}{c}01.901 \\
(0.0462)\end{array}$ & $\begin{array}{c}0.2828 \\
(0 \cdot 1010)\end{array}$ \\
\hline $80-90$ & $\begin{array}{c}0.1790 \\
(0.0490)\end{array}$ & $\begin{array}{r}0.2687 \\
(0.1116)\end{array}$ & $\begin{array}{c}0.3584 \\
(0.0798)\end{array}$ & $\begin{array}{c}0.5485 \\
(0.1546)\end{array}$ & $\begin{array}{c}0.8157 \\
(0.3954)\end{array}$ \\
\hline $90-100$ & $\begin{array}{c}0.7407 \\
(0.4176)\end{array}$ & $\begin{array}{c}1 \cdot 1981 \\
(0.4502)\end{array}$ & $\begin{array}{c}1.9188 \\
(0.3842)\end{array}$ & $\begin{array}{c}2 \cdot 3873 \\
(0.7049)\end{array}$ & $\begin{array}{c}3.0159 \\
(1 \cdot 2064)\end{array}$ \\
\hline $0-100$ & $\begin{array}{c}0.4705 \\
(0.0793)\end{array}$ & $\begin{array}{c}0.6540 \\
(0.1550)\end{array}$ & $\begin{array}{c}0.7434 \\
(0.1739)\end{array}$ & $\begin{array}{c}0.8139 \\
(0.1016)\end{array}$ & $\begin{array}{c}1 \cdot 1209 \\
(0 \cdot 2848)\end{array}$ \\
\hline
\end{tabular}

total effective time $\left(\right.$ teff $\left._{\mathrm{T}}\right)$ was calculated as described elsewhere. ${ }^{2}$ The partial effective times (teff $_{p-1} \ldots$ teff $\left._{p-10}\right)$ were calculated in segments of the FVC-t curve corresponding to $10 \%$ parts of the FVC (fig 1) using up to five points in seg-

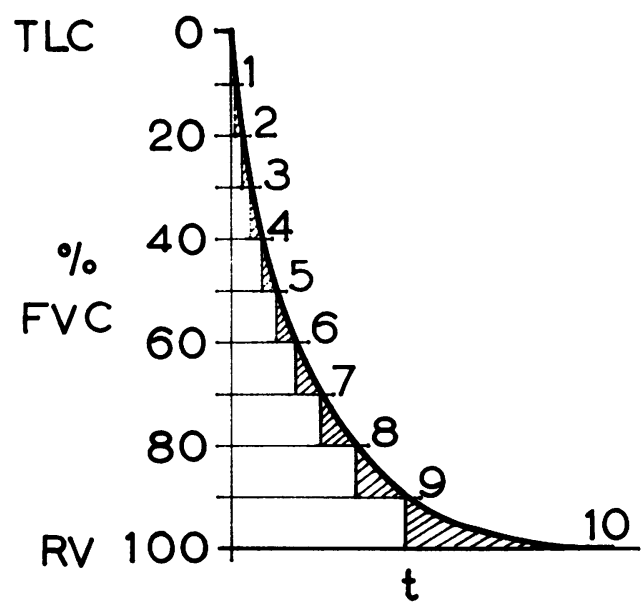

Fig 1 Expiratory forced vital capacity versus time curve (FVC-t curve). The FVC in litres is divided into $1010 \%$ parts. $A$ parallel line to the time axis drawn from each $10 \%$ point on the FVC axis intercepts the curve at points numbered from 1 to 10 , separating the curve into 10 segments. The effective time was calculated in the whole FVC-t curve $\left(\right.$ teff $\left._{\mathrm{T}}\right)$ and in each of the triangles (dashed areas) (teff $f_{\mathrm{p}}$ ). Time $(t)$ in seconds. ments with extreme curvilinearity. The method $\stackrel{\vec{F}}{\stackrel{\vec{S}}{9}}$ for the calculation of teff $p$ was in principle the same as that for the calculation of teff $\mathrm{T}_{\mathrm{T}}$, but it should be emphasised that teff $_{T}$ does not equal $\frac{\bar{\omega}}{7}$ the sum of the partial effective times (table). In $\stackrel{\mathbb{\Omega}}{\AA}$ the same curve FVC, $\mathrm{FEV}_{1}$, and $\mathrm{FEV}_{1} / \mathrm{FVC}$ \% were also measured.

\section{Results}

The results for the total effective time $\left(\right.$ teff $\left._{T}\right) \overrightarrow{\vec{x}}$ and the partial effective time in every $10 \%$ FVC segment of the FVC-t curve (teff p in the $80 \mathrm{cr}$ normal subjects aged 20-69 years are shown in $\omega$ the table. In normal subjects the partial effective ov time (teff $f_{p}$ becomes longer towards the residual o volume $(100 \% \mathrm{FVC})$, especially beyond the $50 \%$ level of the FVC and this is more pronounced in $?$ the older age groups (fig 2). The results in the 30 patients are expressed as the ratio of the $\vec{\bullet}$ effective time (total or partial) of the patient over $\$$ the corresponding normal mean effective time (teff/teff ${ }_{N}$ ) (fig 3-5). In the normal subjects the ratio teff/teff ${ }_{N}$ lies within the limits of $\pm 1 \mathrm{SD} /$ mean about unity. In the patients, the ratios teff $_{p} /$ teff $_{x, p}$ in the segments of the curve from TLC level ( $0 \%$ FVC) till $50 \%$ FVC are omitted as they are within normal limits. Beyond this $\overrightarrow{\overrightarrow{0}}$ level $(50 \%$ FVC) towards the residual volume $\left(100 \%\right.$ FVC) the ratio teff $/$ teff $_{\mathrm{S}}$ becomes greater than normal (figs 3-5). At the $80-90 \%$ FVC segment of the curve the ratio teff ${ }_{p-9} /$ teff $_{N, p-9}$ is higher than normal in all the patients of all ages. At the tenth segment $(90-100 \%$ FVC) the ratio ? teff $_{p-10} /$ teff $_{N, p-10}$ is also greater than normal in all the patients except in the age group 50-59 years. In the two patients suffering from chronic bronchitis with low $\mathrm{FEV}_{1} / \mathrm{FVC}$ ratio the ratio teff $p$ / teff $x_{x ; p}$ in all the segments of the $F C V-t$ curve is $\frac{\text { O }}{2}$ greater than normal with the exception of the $\frac{D}{D}$ first segment $(0-10 \%$ FVC) and, in one patient aged 52 years, of the tenth $(90-100 \%$ FVC) in No which teff ${ }_{p} /$ teff $_{N, p}$ are within normal limits.

\section{Discussion}

The total effective time of the $F V C-t$ curve $O$ $\left(\right.$ teff $\left._{T}\right)$ reflects the events throughout the whole $\mathbb{\Phi}$ curve and in this respect this parameter is a sensi- + tive index of the status of the major and the small airways. It has been shown that teff ${ }_{\mathrm{T}}$ is $\frac{\mathrm{O}}{\mathbb{D}}$ longer than normal in patients with airways $\stackrel{?}{?}$ obstruction. ${ }^{2}$ However, in certain cases of simple $\stackrel{\AA}{\varrho}$ chronic bronchitis with normal $\mathrm{FEV}_{1} / \mathrm{FVC}$ and rarely in chronic bronchitis with low $\mathrm{FEV}_{1} / \mathrm{FVC}^{\circ}$ ratio, the total effective time $\left(\right.$ teff $\left._{\mathrm{T}}\right)$ is slightly 


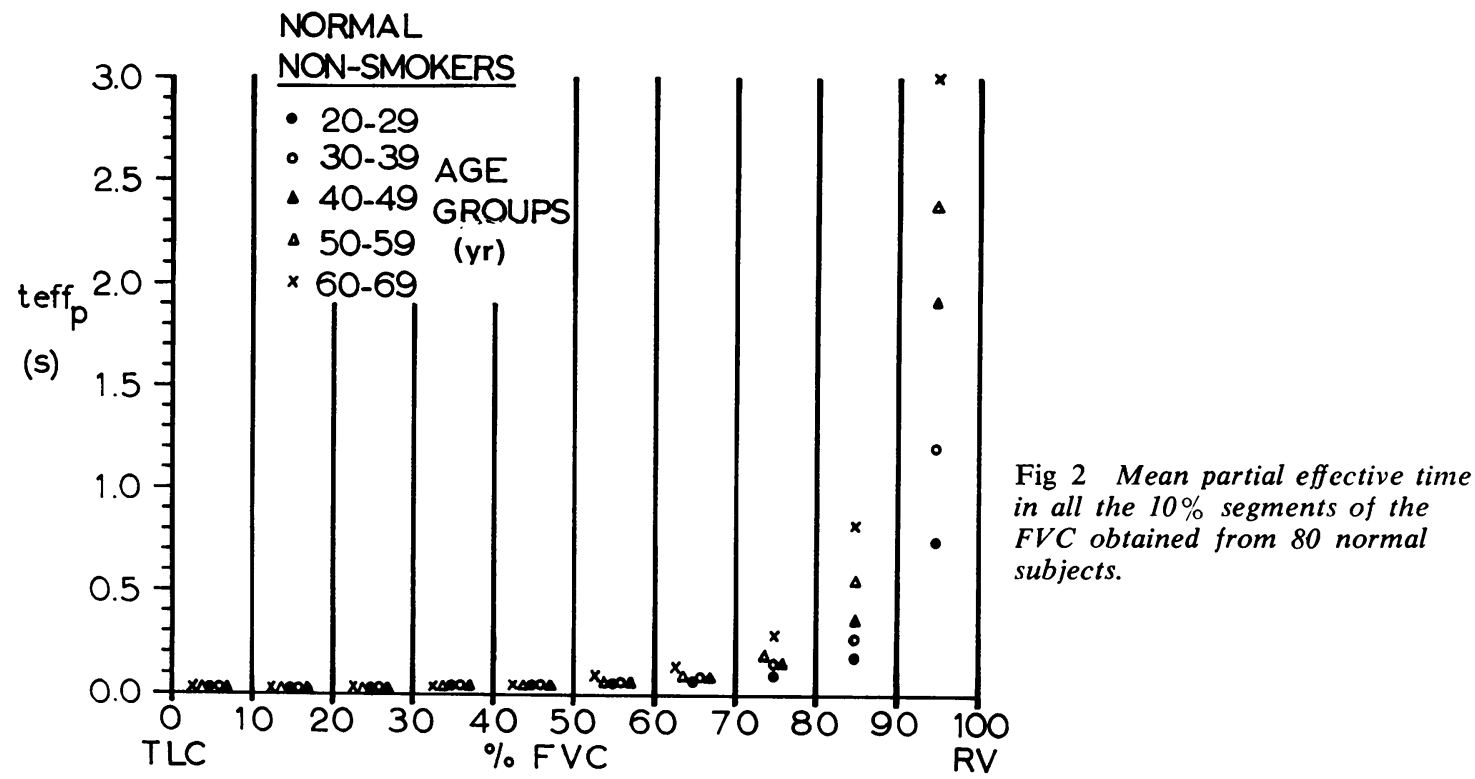

longer than the upper normal limit and within the range of the repeatability error of this para-

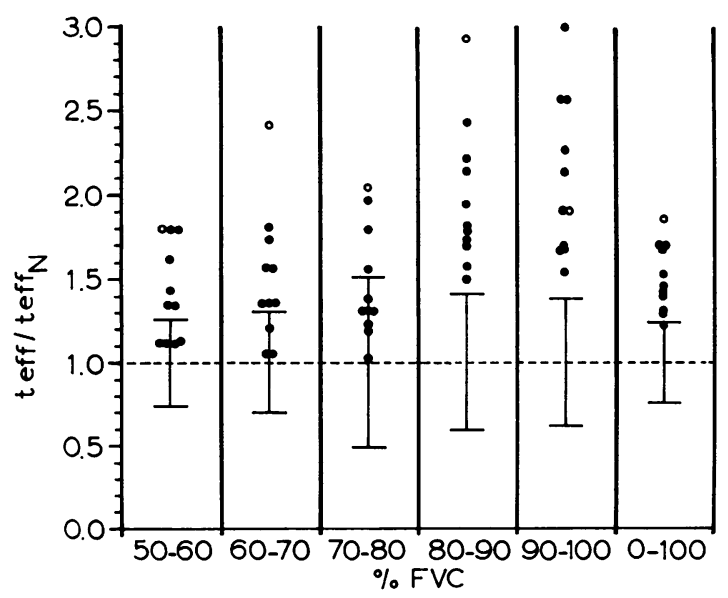

Fig 3 Ratio of the effective time of the patient (teff total or partial) over the normal mean value of the corresponding effective time (teff ${ }_{N}$ ) at several segments of the FVC and at the whole curve $(0-100 \%$ FVC $)$. The dashed line $\left(\left(\right.\right.$ teff $/$ teff $\left.\left._{X}\right)=1\right)$ denotes that the total or partial effective time of the patient is equal to the normal mean value. The horizontal lines about unity correspond to the coefficient of variation (SD/mean). Closed circles correspond to the patients with simple chronic bronchitis (normal FEV ${ }_{1} / F V C$ ratio) and open circles to those with chronic bronchitis and low FEV $/ F V C$ ratio. The patients in this diagram belong to the 30-39 years age group. meter. This error is usually less than $0.15 \mathrm{~s}$ but it may be as long as $0.2 \mathrm{~s}$ for a 0.11 difference in FVC in five consecutive trials. Furthermore, we noticed that $F V C-t$ curves corresponding to different degree of airways obstruction, as judged from the variety of the $\mathrm{FEV}_{1} / \mathrm{FVC}$ ratios, may have the same total effective time (teff $T$ ) (unpublished data). The morphology of the spirogram is of utmost importance as it accounts for the above conditions. The shape of the $\mathrm{FVC}-\mathrm{t}$ curve has not not yet been extensively studied. The complete $\mathrm{FVC}-\mathrm{t}$ curve is too alinear to be expressed by a single volume/time slope. However, most

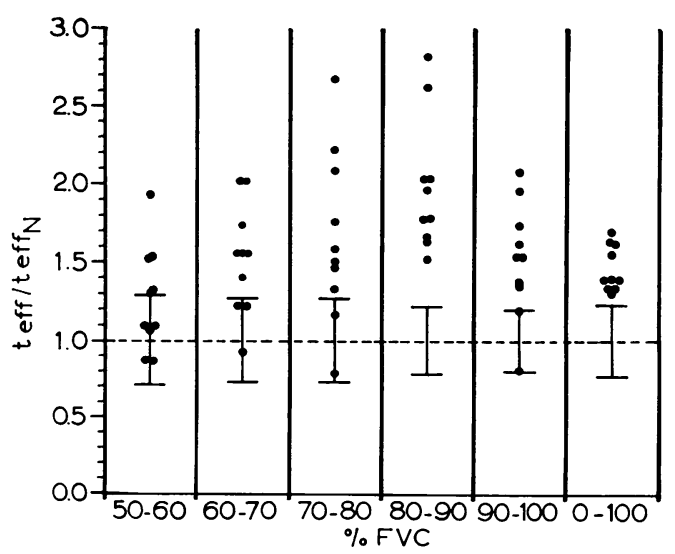

Fig 4 Ratio of effective time of patients to normal mean value of effective time for subjects aged 40-49 years. Sy'mbols as in fig 3. 


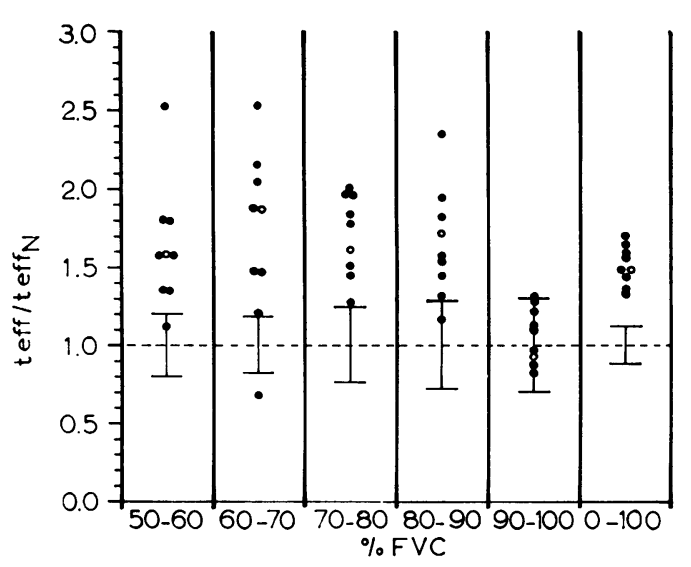

Fig 5 Ratio of effective time of patients to normal mean value of effective time for subjects aged 50-59 years. Symbols as in fig 3.

of the $10 \%$ FVC segments of the curve may be considered as virtually linear so that the slope of each segment is nearly equal to $0 \cdot 1 \mathrm{FVC} / 2$ teff $\mathrm{p}$. Slopes of segments may be used to describe the curvilinearity of the spirogram and for discrimination between maximal expirograms with nearly normal or even with the same total effective time. We prefer to use the effective time only, instead of the slope, because this parameter is mainly age-and not height-or sex-dependent. ${ }^{2}$ Because the total effective time of the FVC does not equal the sum of the partial effective times, a normal teff ${ }_{T}$ in a patient with mild airways obstruction does not exclude the possibility that there may be an abnormally long teff $f_{p}$ in one or two lower $10 \%$ segments of the FVC. Accordingly, the partial effective times are useful parameters of lung function not only to show the segments of the spirogram affected by disease but also to detect changes that cannot be depicted by the total effective time. The results obtained in normal non-smoking subjects show that the partial effective times remain practically unaltered from TLC till about the $50 \%$ level of the FVC in all the age groups from 20 to 69 years. Beyond this level ( $50 \%$ FVC), the partial effective time increases towards the residual volume especially in the older age groups. The older the normal subject the longer becomes the effective time (fig 2). In the patients studied the partial effective times at the region $0-50 \%$ FVC remained within the normal limits while in the second half of the FVC $(50-100 \%$ FVC) they $\stackrel{\vec{F}}{\stackrel{\vec{S}}{9}}$ became definitely longer than in normals. It is interesting that the partial effective time at the 믐 last $10 \%$ part of the FVC (teff $p-10$ ) in the age $\frac{\bar{\sigma}}{\sigma}$ group 50-59 years is within the normal range. $\stackrel{\otimes}{\alpha}$ This may be explained by the inability of the patients at this age to sustain maximum effort for long. It is also obvious that the partial effec- $\stackrel{\circ}{\circ}$ tive time at the $80-90 \%$ FVC segment $\left(\right.$ teff $\left._{p-9}\right) \overrightarrow{\vec{\omega}}$ in all the age groups is abnormally long in all the patients studied, except in one. This finding sug- $\vec{x}$ gests that the teff $f_{p-9}$ may be considered as the $\dot{\omega}$ most sensitive parameter for the early detection or of small airways obstruction in all the age groups $\sigma$ as compared to the rest of the partial effective of times, the total effective time, and the $\mathrm{FEV}_{1}$ / 음 FVC ratio.

We would like to thank Dr Neil Pride for his most helpful criticism.

\section{References}

1 Fish J, Menkes H, Rosenthal R, Summer W, Norman P, Permutt $\mathbf{S}$. The effect of acute bronchospasm on the distribution of transit times $\frac{2}{\Phi}$ during forced expiration. Am Rev Respir Dis 1974; 109:700.

2 Jordanoglou J, Koursouba E, Lalenis C, Gotsis 3 T, Kontos J, Gardikas C. Effective time of the forced expiratory spirogram in health and air-? ways obstruction. Thorax 1979; 34:187-93.

3 Neuburger N, Levison H, Bryan AC, Kruger K. 으 Transit time analysis of the forced expiratory $\underset{x}{\stackrel{0}{x}}$ spirogram in growth. J Appl Physiol 1976; 40: 329-32.

4 Neuburger N, Levison H, Kruger K. Transit time $\delta$ analysis of the forced expiratory vital capacity in cystic fibrosis. Am Rev Respir Dis 1976; 114: 0 753-9.

5 Tockman M, Menkes H, Cohen B et al. A com- $-\frac{D}{0}$ parison of pulmonary function in male smokers and nonsmokers. Am Rev Respir Dis 1976; 114: م 711-22.

6 Webster PM, Zamel N, Bryan AC, Kruger K. N Volume dependence of instantaneous time con- $\omega$ stants derived from the maximal expiratory flowvolume curve. Am Rev Respir Dis 1977; 115:0 805-10.

7 Cotes JE. Lung function: assessment and appli- $\stackrel{\oplus}{+}$ cation in medicine. Second edition. Oxford: 7 Blackwell Scientific Publications, 1966: 136-7, 381. 